\title{
Pkm Peningkatan Potensi Batik Melalui Perlindungan Hki Dan Penguatan Manajemen Pemasaran Berbasis Tik Di Desa Silowogo Kecamatan Bungatan Kabupaten Situbondo
}

\author{
Irwan Yulianto, Ali Uraidy \\ Universitas Abdurachman Saleh, Situbondo \\ Email : irwan.yuliantol767@gmail.com
}

\begin{abstract}
Abstrak
Tujuan dan target yang ingin dicapai dalam PKM ini adalah mendorong serta mendukung usaha batik di daerah Situbondo yang memiliki keinginan yang tinggi untuk mengembangkan usaha batik baik di kawasan lokal maupun internasional yang aman, nyaman dan berkelanjutan yang berpedoman pada kepastian hukum dengan memberikan pengetahuan serta pendampingan guna meningkatkan keterampilan dalam proses pendaftaran hak cipta motif batik serta pendampingan pemasaran batik khas Situbondo. Metode yang digunakan berupa pendampingan pendaftran hak atas hak cipta motif batik khas Situbondo pada Kementerian Hukum dan HAM RI dan peningkatan manajemen pemasaran berbasis teknologi infomasi. Hasil yang dicapai antara lain yaitu keluarnya bukti pendaftaran hak cipta motif batik dan nomor pencatatan pada Kementrian Hukum dan HAM RI
\end{abstract}

Kata Kunci : Hak cipta, batik, pemasaran, TIK

\section{PENDAHULUAN}

Secara geografis Kabupaten Situbondo berada di pesisir utara pulau jawa yang wilayahnya dari ujung barat sampai ujung timur merupakan daerah pantai sepanjang $141 \mathrm{~km}$, sehingga situbondo memiliki kekayaan laut yang melimpah. Situbondo merupakan daerah yang memiliki sumber daya ikan cukup besar. (Puryantoro,2017). Sumber daya ikan tersebut berada di Laut Jawa yaitu sebelah barat dan utara wilayah Kabupaten Situbondo, serta di perairan umum yang tersebar hampir diseluruh Kecamatan di Kabupaten Situbondo. Keindahan panorama pantai dan wisata bahari menjadi suatu ikon Kabupaten situbondo. Selain itu Kabupaten Situbondo juga sangat kaya akan kerang yang dapat dimanfaatkan oleh para pekerja seni masyarakat situbondo menjadi kerajinan kerang yang sangat indah dan dikenal oleh dunia.

Batik Situbondo adalah Batik asli yang berasal dari kabupaten Situbondo. Motif batik ini kebanyakan bermotif kerang karena utara Kabupaten Situbondo ini terdapat pesisir. Sejarah batik telah sejak lama, banyak versi tentang keberadaan batik di Situbondo zaman dahulu. Mulai dari batik yang ada di desa Selowogo Kecamatan Bungatan, menurut penjelasan dari salah satu narasumber bahwa batik di 
Situbondo telah ada sejak zaman penjajahan Belanda. Batik di Situbondo sebenarnya sudah ada sejak tahun 1970 atau sebelumnya, hal ini dapat dibuktikan dengan peninggalan kain batik yang ada di Desa Peleyan Kecamatan Kapongan (namun lebih dikenal dengan cotto'an). Namun seiring beberapa permasalahan yang terjadi, menyebabkan batik yang ada di Situbondo (dengan motif seperti motif madura) mati suri. Perkembangan Batik Khas Situbondo mulai dengan babak baru sejak tahun 1994 di Desa Selowogo Kecamatan Bungatan. (wikipedia.org)

Pada www. kecamatanbungatan.weebly.com menyebutkan bahwa batik selowogo ditetapkan sebagai batik khas situbondo. Batik ini mempunyai motif khas kelautan yang merupakan ciri utama Situbondo. Selowogo adalah desa di kecamatan bungatan. Jarak dari pantai wisata pasir putih lebih kurang $7 \mathrm{~km}$ arah selatan. Jarak dari kota situbondo lebih kurang $30 \mathrm{~km}$ arah barat. Jarak dari surabaya lebih kurang $170 \mathrm{~km}$ arah timur. Jalan ke desa selowogo dapat dilalui dengan mudah menggunakan kendaraan pribadi maupun kendaraan umum, karena telah diaspal.

Permasalahan yang dihadapi oleh UKM Batik Desa Silowogo dalam Program Kemitraan Masyarakat adalah persoalan kurangnya pemahaman (verstehen/understanding), pengetahuan (knowledge), tata cara (technic) untuk mendapatkan perindungan hukum bagi para pengrajin yaitu produk batik yang dihasilkan. Persoalan tersebut merupakan kendala bagi para pengrajin batik untuk bisa mengembangkan usaha batik yang aman, nyaman dan memiliki kepastian hukum, ketidaktahuan para pengrajin batik akan pentingya perlindungan hukum terhadap produk batik yang dihasilkan menjadi persoalan penting untuk dapat diselesaikan.

Di kampung batik Desa Silowogo Kab. Situbondo banyak pengrajin batik tidak mengetahui jika batik merupakan produk yang dapat diberikan kepastian hukum yaitu pemberian hak atas produk batik, dalam hal pemberian hak yaitu dengan cara didaftarkan di Dirjen HAKI sesuai Undang-undang No 19 tahun 2002 Tentang Hak Cipta bahwa manfaat dari pemberian hak oleh pemegang hak desain industri untuk menikmati manfaat ekonomi dari suatu desain industri dan dapat diberikan perlindungan, sehingga dapat memberikan keamanan, kenyamanan dan kepastian hukum bagi para pengrajin batik. Permasalahan mengenai perlindungan hukum ini tidak hanya pada UKM yang ada di Situbondo namun juga terjadi pada UD Barokah J- Kumbu" dan "UD Dua Bola Randos" di kabupaten Lumajang belum didaftarkannya merek dagang yang mitra miliki ke Kementrian Hukum dan Hak Asasi Manusia Direktorat Jenderal Hak Atas Kekayaan Intelektual,sehingga berpotensi tidak terlindunginya merek dagang mitra secara hukum.(Ratnaningsih $\mathrm{dkk}, 2017)$.

Menurut Undang-Undang No.19 Tahun 2002 hak cipta adalah hak eksklusif bagi pencipta atau penerima hak untuk mengumumkan atau memperbanyak ciptaannya atau memberikan izin untuk itu dengan tidak mengurangi pembatasanpembatasan menurut peraturan perundang-undangan yang berlaku. Sedangkan menurut Auteurswet 1912 pasal 1 menyebutkan bahwa Hak Cipta adalah hak tunggal dari pencipta, atau hak dari yang mendapat hak tersebut, atas hasil ciptaannya dalam 
lapangan kesusasteraan, pengetahuan dan kesenian, untuk mengumumkan dan memperbanyak dengan mengingat pembatasan-pembatasan yang ditentukan oleh undang-undang. (BPHN, 1976 dalam Muliani, A. R, 2007).

Di Desa para pengrajin batik masih menggunakan cara pandang tradisional mereka tidak memikirkan tentang pentingya perlindungan hukum tetapi para pengrajin batik haya berpikir yaitu bagaimana menghasilkan produk design batik yang sebanyak-banyakya dan dapat memasarkan produk batik yang dihasilkan, dalam hal ini para pengrajin batik sangat mengesampingkn perlindungan hukum bagi keberlangsungan usaha batik, padahal pada saat ini sudah masuk pasar bebas ASEAN maka diperlukan kesiapan bagi para pengrajin batik dalam hal persaingan bebas yang pasti harus memiliki kualitas, kuantitas dan kepastian akan produk hasil karya paraa pengrajin batik, yang sekarang ini hasil produk para pengrajin sudah memiliki pangsa pasar yang luas di Indonesia dan kedepan para anggota paguyuban batik Situbondo berencana memasarkan produk batik di negara tetangga sehingga sangat diperlukan perlindungan hukum dan kepastian hukum.

Pemerintah Daerah, Instasi terkait dalam hal ini Dirjen HKI harus dapat bekerjasama untuk memberikan pelayanan, kemudahan dan sebagai motor penggerak para pengrajin batik untuk berkembang di pasar lokal maupun internasional dengan perlindunagn hukum apalagi ekonomi sekarang sudah berkembang dan berubah para pengrajin harus bisa menyesuaikan perkembangan ekonomi untuk tetap bisa bersaing di pasar bebas dan mempuyai keberlanjutan usaha dengan cara memiliki kualitas dan kepastian hukum atas produk batik yang telah dihasilkan, dalam hal ini pemerintah, khususya pemerintah kabupaten Situbondo harus berperan aktif untuk memberikan pelayanan dan jaminan keamanan usaha bagi para pengrajin batik.

Selain itu, persoalan yang juga dihadapi oleh pengrajin batik Situbondo adalah masalah pemasaran yang hingga saat ini masih menggunakan cara-cara konvensional. Oleh karena itu, diperlukan upaya-upaya penyadaran arti pentingnya melindungi karya intelektual sebagai ide-ide kreatif masyarakat pengrajin seni di kabupaten Situbondo, serta membantu para pengrajin dalam memanfaatkan teknologi informasi dan komunikasi (TIK)

Tujuan dan target yang ingin dicapai dalam PKM ini adalah mendorong serta mendukung usaha batik di daerah Situbondo yang memiliki keinginan yang tinggi untuk mengembangkan usaha batik baik di kawasan lokal maupun internasional yang aman, nyaman dan berkelanjutan yang berpedoman pada kepastian hukum dengan memberikan pengetahuan serta pendampingan guna meningkatkan keterampilan dalam proses pendaftaran hak cipta designn seni batik serta pendampingan pemasaran batik khas Situbondo.

\section{METODE PELAKSANAAN}

Metode pendekatan yang ditawarkan dalam mengatasi berbagai permasalahan mitra adalah melalui pembinaan HKI yang terintegrasi antara bidang hukum, teknologi 
informasi dan komunikasi sehingga Batik khas Situbondo dapat berkembang dan bersaing secara global.

Langkah-langkah yang dilakukan untuk mengatasi persoalan mitra sebagaimana yang telah diuraikan sebelumnya adalah sebagai berikut:

1. Penyusunan buku panduan HKI dengan bahasa yang sederhana, penyusunan panduan pembinaan kesadaran hukum tentang HKI dan peningkatan manajemen pemasaran berbasis TIK.

2. Pelatihan TIK untuk memperkuat manajemen pemasaran;

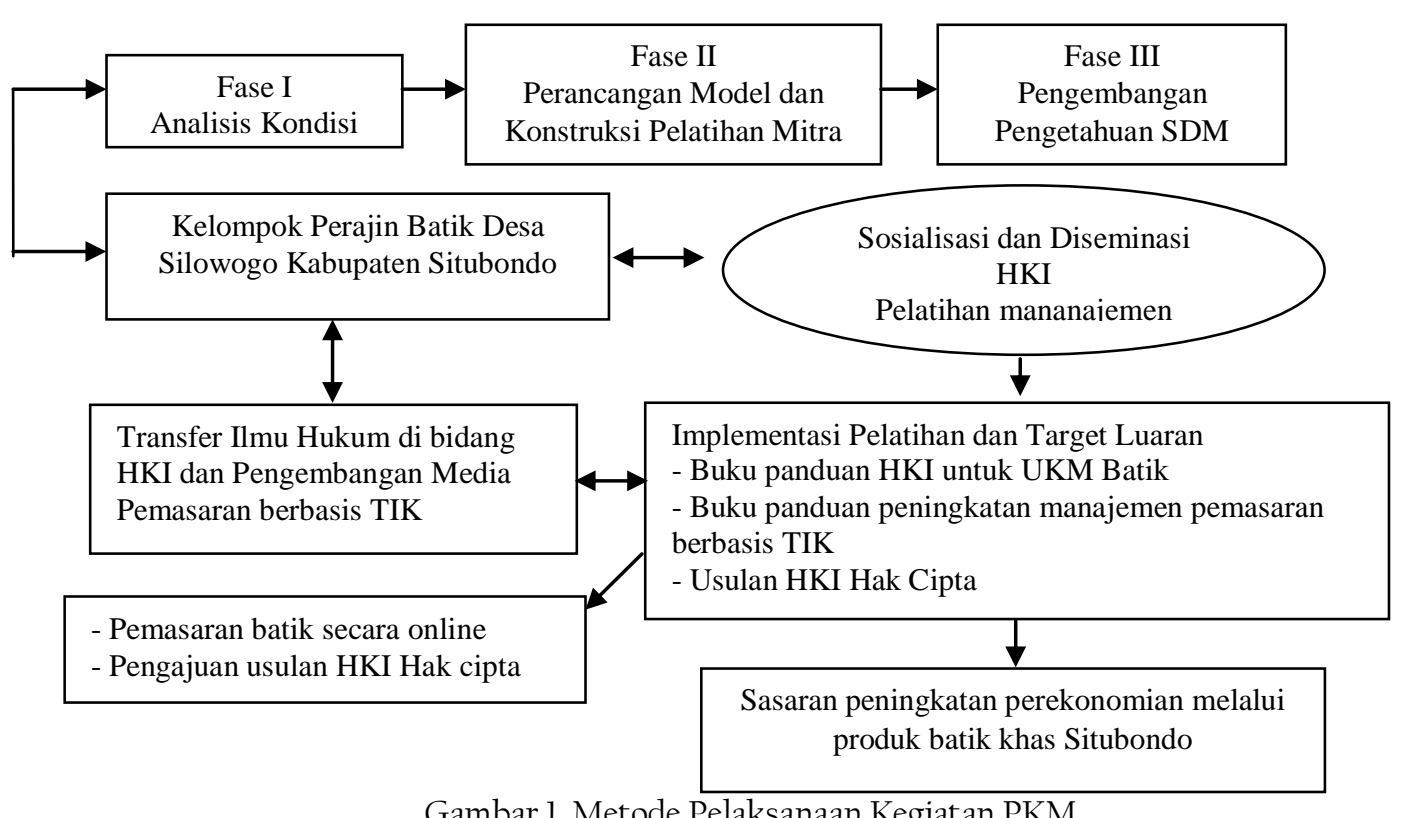

Gambar l. Metode Pelaksanaan Kegiatan PKM

Berdasarkan skema tersebut diatas, adapun prosedur kerja yang dilakukan untuk mendukung realisasi metode yang ditawarkan adalah terfokus pada upaya peningkatan pemahaman tentang HKI dan peningkatan keterampilan pemanfaatan TIK dalam memasarkan produk Batik khas Situbondo. Kegiatan akan dikemas dalam 3 (tiga) tahapan yakni:

1. tahap sosialisasi dan diseminasi tentang HKI

2. tahap pelatihan penggunaan TIK dalam menciptakan pemasaran berbasis IT (pemasaran secara online), dan

3. tahap pendampingan pengisian formulir pendaftaran HKI terhadap hak cipta kerajinan batik Situbondo.

\section{HASIL DAN PEMBAHASAN}

Melihat potensi ekonomi yang begitu besar yang bisa diperoleh dari motif motif batik di Desa Silowogo bila menggunakkan potensi HKI yang dimiliki oleh masing-masing motif, maka sudah sangat wajar bila para pengrajin tersebut memiliki 
pemahaman yang memadai tentang berbagai macam peraturan dan undang-undang yang mengatur tentang perlindungan Hak Kekayaan Intelektual bagi produk mereka. Menurut Muliani, A. R. (2007) keberadaan hukum hak cipta tidaklah senantiasa memberikan perlindungan hukum pada si pemegang haknya saja, namun melindungi juga pada kepentingan yang lebih umum.

Mitra UKM batik di Desa Silowogo kecamatan Bungatan kabupaten Situbondo adalah UD. Batik Rengganis. Tim pelaksana mengawali program pendampingan dengan melakukan sosialiasasi kepada owner dan 20 karyawan UD. Batik Rengganis mengenai pentingnya perlindungan hukum HKI hak cipta untuk seni batik. Selain itu mitra juga dibekali dengan pemanfaatan teknologi informasi dalam pemasaran bantik sehingga produk akan lebih dikenal lebih luas dan akan berdampak pada permintaan batik khas Situbondo. Teknologi informasi yang digunakan dapat berupa pemasaran melalui media online.

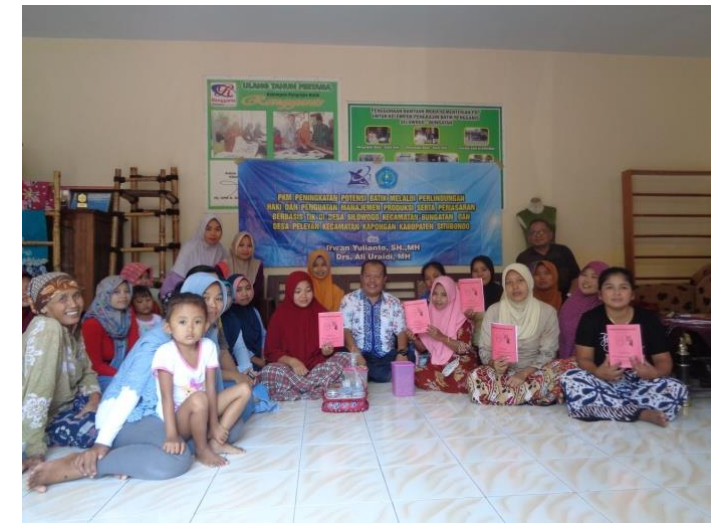

Gambar 2. Sosialisasi HKI pada owner dan karyawan UD. Batik Rengganis

Selanjutnya menelusuri data yang dimiliki mitra sebagai persyaratan yang harus dilengkapi sebelum mendaftarkan HKI Hak Cipta. Kemudian tim pelaksana berkoordinasi dengan Dinas Perindustrian dan Perdagangan kabupaten Situbondo untuk meminta surat pengantar agar dapat mendaftarkan Hak Cipta melalui jalur usaha mikro kecil dan menengah (UMKM) untuk disampaikan pada Direktur Jenderal Kekayaan Intelektual Kementrian Hukum dan HAM RI.

Berkaitan dengan hak cipta motif yang disepakati untuk didaftarkan, UD. Batik Rengganis menentukan 4 (empat motif) batik yang menjadi unggulan yaitu motif tali percing, ojung, ler keleran dan kerang gempel. Pendaftaran Hak Cipta dilakukan secara online melalui Sentra Hak Kekayaan Intelektual Universitas Abdurachman Saleh Situbondo pada tanggal 25 Mei 2018. Tim Pelaksana PKM juga mengajak mahasiswa untuk bisa dilibatkan dalam proses pendaftaran Hak Cipta agar mahasiswa paham bagaimana prosedur mendaftarkan hak cipta sehingga diharapkan mahasiswa paham selain teori juga praktek pendaftaran hak cipta.

Register pendaftaran hak cipta telah diterima dari Kementrian Hukum dan HAM RI yang dapat diuraikan sebagai berikut: 
1. Motif Batik Khas Situbondo "Ojung"

No Permohonan : EC00201813820

Tanggal Permohonan : 25-05-2018

Tanggal Diterima : 31-05-2018

Nomor Pencatatan : 000109385

2. Motif Batik Khas Situbondo "TALÈ PERCING"

No Permohonan : EC00201813821

Tanggal Permohonan : 25-05-2018

Tanggal Diterima : 31-05-2018

Nomor Pencatatan : 000109386

3. Motif Batik Khas Situbondo "LÈR KÈLÈRAN"

No Permohonan : EC00201813822

Tanggal Permohonan : 25-05-2018

Tanggal Diterima : 22-06-2018

Nomor Pencatatan : 000110276

4. Motif Batik Khas Situbondo "Kerang Gempel"

No Permohonan : EC00201813823

Tanggal Permohonan : 25-05-2018

Tanggal Diterima : 22-06-2018

Nomor Pencatatan : 000110277

Dengan diterimanya dan tercatatnya motif batik khas Situbondo yang diusulkan ke Direktorat Jenderal Kekayaan Intelektual Kementrian Hukum dan HAM RI maka motif tersebut telah terlindungi secara hukum. Penyerahan sertifikat surat pencatatan ciptaan dilakukan pada tanggal 3 Juni 2018.

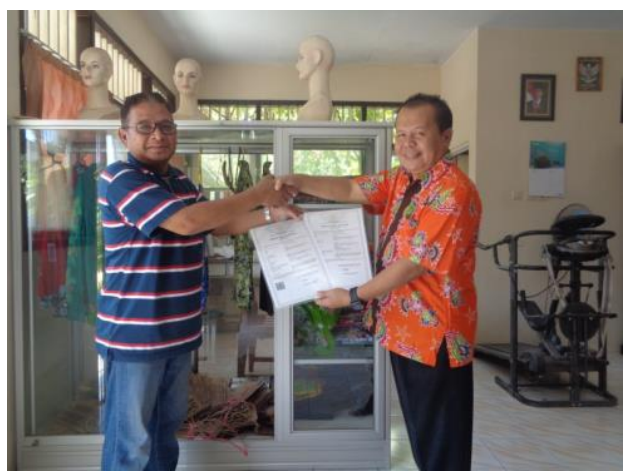

Gambar 3. Penyerahan sertifikat surat pencatatan ciptaan

Pelaksanaan program Pengabdian kepada Masyarakat ini secara umum berjalan dengan baik, hal ini ditunjukkan dengan antusiasme owner dan peserta dalam mengikuti seluruh rangkaian kegiatan yang sudah dijadwalkan. Mitra memiliki pemikiran terbuka dan mau menerima saran dan masukan demi perlidungan hukum dan pengembangan usaha serta peningkatan produktivitas batik khas Situbondo. 
Kesimpulan

\section{SIMPULAN DAN SARAN}

Kesimpulan Melalui program PKM ini ditemukan beberapa permasalahan mitra berupa aspek perlindungan hukum atas hak cipta motif batik dan aspek pemasaran sudah dapat diselesaikan dengan beberapa kegiatan berupa: pendampingan pendaftaran hak cipta mitra pada kementrian hukum dan HAM RI dengan keluarnya nomor pencatatan motif batik dengan demikian motif batik yang telah diterima secara hukum terlindungi dari upaya penjiplakan, peniruan, atau halhal negative lainnya dari pihak lain terhadap hak cipta yang telah didaftarkannya. Pada kegiatan PKM ini juga dilakukan pendampingan pemasaran batik Situbondo dengan memanfaatkan teknologi informasi seperti media sosial agar dapat membantu mitra meningkatkan produksi, publikasi mitra dan kegiatan PKM melalui media radio, media cetak agar usaha mitra maupun kegiatan PKM program hibah pengabdian masyarakat dari Kemenristek Dikti ini dapat diketahui masyarakat luas

Saran

Motif batik yang dibuat oleh pengrajin batik Situbondo sangat banyak sehingga perlu adanya kesadaran yang berkelanjutan untuk UKM batik agar motifmotif tersebut didaftarkan hak ciptanya ke Kementerian HAM RI supaya dapat terlidungi secara hukum. Pendaftaran hak cipta yang mudah dan praktis dapat melalui sentra HKI Universitas Abdurachman Saleh Situbondo.

\section{DAFTAR PUSTAKA}

Muliani, A. R. (2007). Perlindungan Hukum Hak Kekayaan Intelektual Bagi Usaha Kecil di Bidang Industri Kerajinan di Wilayah Kabupaten Bantul (Studi Kasus pada Kerajinan Bidang Pandan dan Enceng Gondok) (Doctoral dissertation, Program Pasca Sarjana Universitas Diponegoro).

Puryantoro, P. (2018). PKM Desain Labelling Kemasan Kerupuk Ikan Pada Industri Kecil Menengah di Desa Pesisir Kecamatan Panarukan Kabupaten

Situbondo. Warta Pengabdian, 12(1), 233-238.

Ratnaningsih, R., Yuraida, N., \& Azizah, S. U. (2017). IMPEMENTASI

PEMBERDAYAAN MITRA PEREMPUAN DALAM PRODUKSI "SALE

PISANG” SERTA PERLINDUNGAN MEREK DAGANGNYA. Jurnal

Pengabdian Masyarakat IPTEKS, 3(1).

https://id.wikipedia.org/wiki/Batik_Situbondo

https://kecamatanbungatan. weebly.com/batik-selowogo.html 